\title{
TRAGANJE ZA NACIONALNIM IDENTITETOM U ISTORIOGRAFIJI I KULTURI SRPSKOG BAROKA I PROSVETITELJSTVA
}

\section{Nikola Samardžić}

UDK: 930:323.1(=163.41)“16/17“"

Apstrakt: U srpskom predrevolucionarnom društvu, jedna od posebnosti procesa nacionalne emancipacije bila je unutrašnja borba između tradicionalne hijerarhije i novih ustanova narodne samouprave. Važna dihotomija bila je i u neprilagodljivosti usmene narodne kulture, koja se ostvarila potom u Srpskoj revoluciji, s prosvetiteljskim diskursom podunavskog građanstva i klera, otuđenim od nepismenog seljačkog, zatim i ustaničkog društva. Nacionalna mitologija formirala se u ideologiziranju prošlosti u nacionalnim epovima, često sa zajedničkim temama i ličnostima koje su susedne nacije delile, ili u pokušajima racionalizacije u istoriografiji. U hrvatskom ili srpskom slučaju nacije su, isprva, nedvosmisleno bile ideološke konstrukcije. Pozivale su se na južnoslovensko poreklo, kulturno jedinstvo, ili ulogu u borbi protiv Turaka. Istoriografija srpskog baroka prati se tek od, u svemu izuzetne, pojave grofa Đorđa Brankovića. Karakterologija njegovih ideja i poruka delimično pripada poslednjoj deceniji XVI veka, obeleženoj ideološkom fantastikom obnovljenih sanjarenja o krstaškom poduhvatu koji će okončati osmansku vladavinu i osloboditi hrišćanske narode i hrišćanske svetinje. Branković je takođe prerano pozivao na opšti oslobodilački pokret čiji je ilirizam najavljivao, vek ranije, nacionalni karakter Srpske revolucije, čiji se modernitet zasnivao i na ekonomskoj moći, sasvim skorašnjoj, političkog i vojnog liderstva, i na uvažavanju ideoloških, nekad $\mathrm{i}$ istoricističkih poruka srpskih prosvetitelja, čiji su koreni duboko u srpskom baroku. Gotovo sličnom putanjom je Vuk Stef. Karadžić, sa osloncem na Dositeja Obradovića koji je u pripadao i prethodnoj prosvetiteljskojepohi, iskoračio u kulturu evropskog romantizma.

Ključne reči: nacionalni identitet, Srbi, Hrvati, istoriografija, kultura, barok, prosvetiteljstvo

I

rvatska i srpska istoriografija nastale su u okolnostima koje su u svemu bile izuzetne. Verovatno nije moguće uspostaviti njihovo potpuno uzajamno razgraničenje. Njihova tumačenja porekla i istorijske uloge narodnih zajednica čine ih takođe naročitim u prošlosti evropske istoriografije.

Hrvatski i srpski nacionalizmi pojavili su se upravo u istoriografskim pokušajima da se tumačenjem prošlosti suštinski izmeni kolektivna stvarnost, neposredno potekla iz pukotina evropskog «Starog režima» i Osmanskog carstva. Traganje za nacionalnim identitetom $\mathrm{u}$ istoriografiji i kulturi hrvatskog i srpskog baroka i prosvetiteljstva odvijalo se u ne- 
koliko različitih sistema, u Habzburškoj monarhiji, Mletačkoj i Dubrovačkoj republici, i u Osmanskom carstvu.

U srpskom predrevolucionarnom društvu, jedna od posebnosti procesa nacionalne emancipacije bila je unutrašnja borba između tradicionalne hijerarhije i novih ustanova narodne samouprave. Važna dihotomija bila je i u neprilagodljivosti usmene narodne kulture, koja se ostvarila potom u Srpskoj revoluciji, s prosvetiteljskim diskursom podunavskog građanstva i klera, otuđenim od nepismenog seljačkog, zatim i ustaničkog društva. Moderna politika gotovo da se poistovećivala s nastankom teritorijalnih država. Moderna nacija nije podrazumevala samo etničku pripadnost, niti se odnosila na jasno definisanu narodnost. Teritorijalne države dobile su asimilirajuću ulogu. Nacionalna mitologija formirala se u ideologiziranju prošlosti u nacionalnim epovima, često sa zajedničkim temama i ličnostima koje su susedne nacije delile, ili u pokušajima racionalizacije u istoriografiji. Evropska moderna je naciju poistovećivala s teritorijalnom državom, koja je naciju tek počinjala oblikovati posredstvom institucija. U hrvatskom ili srpskom slučaju nacije su, isprva, nedvosmisleno bile ideološke konstrukcije. Pozivale su se na južnoslovensko poreklo, kulturno jedinstvo, ili ulogu u borbi protiv Turaka. (U kontrastu s jugoslovenskim primerom, Francuska se iznutra oblikovala u svesti o višeetničnosti nacije, koju čini nekoliko naroda.) Hrvatska ili srpska nacija potekla je iz jedinstvene narodne mase raspoređene u različitim političkim, državnim i ideološkim sistemima.

Svest o zajednici zasnovanoj na jeziku, donekle i kulturi, bila je integrativni činilac ilirizma. Proces nacionalne diferencijacije odvijao se pod uticajima koji su najmanje poticali od stvarnih uzajamnih kulturnih razlika. Izgradnja institucija neposredno je vezana i za izgradnju kolektiviteta, i za proizvodnju nacionalnih posebnosti.

Primetna je zainteresovanost za pitanje nacije u XVIII veku. Pojavljuju se izrazi poput nacionalnog duha, karaktera, bogatstva, ekonomije, institucija. Za Herdera, koji se interesovao za narodnu poeziju, nacija se formira i edukuje posredstvom jezika, i tim putem razvija osećanja za red i čast, preko jezika nacija neguje običaje, i uređuju se ljudski odnosi. Moderna istoriografija bila je usredsređena na nacionalnu istoriju s porivima koji su bili praktični. Od sredine XVIII veka, nacija je postajala nov predmet politike. I u hrvatskoj i srpskoj istoriografiji baroka i prosvetiteljstva patriotizam je počinjao obuhvatati pripadnike svih staleža. Pošto je kultura patriotizma izgubila prethodni feudalni aristokratski ekskluzivitet, ideju nacije je isprva prihvatilo građanstvo koje je upravo u epohi prosvetiteljstva, u kojoj se ekonomski emancipovalo, razvilo jasan društveni identitet.

Istoriografija srpskog prosvetiteljstva XVIII veka ukazivala je da uključivanje u tokove evropeizacije iziskuje nov iskorak od ustaljenog vezivanja, $\mathrm{i} u$ pisanom $\mathrm{i}$ u usmenom pamćenju, za nasleđe feudalne epohe i mitologizirane tradicije. Približavanje savremenoj evropskoj civilizaciji bilo je, i u srpskoj istoriografiji baroka i prosvetiteljstva, oprezno i nepoverljivo, obeleženo nedostatkom oštrih uvida i opštih znanja. Preokret, koji se ipak odigrao, bio je moguć zahvaljujući početku povlačenja Osmanskog carstva iz Podunavlja, nakon dugog trajanja krize u ekonomiji i institucijama. Naporedo s promenom pravnog i političkog statusa srpskih zajednica u Habzburškoj Monarhiji, okončana je prva faza procesa naseljavanja i prilagođavanja koja je trajala pod pritiskom osmanskih osvajanja. Budući da su srpsku kulturu samo doticali, bez važnih uticaja, rani modernizacijski procesi koji su se odigravali $\mathrm{u}$ krupnim potezima ispisanim u istoriji renesanse, reformacije i racionalizma, ta kultura je «nedostatak» ili «prazninu» u začecima modernizacijskog razvoja delimično ispunila tek u epohi baroka. Duboke unutrašnje nedoumice koje je srpska kultura otkrivala dok su se 
njeni prosvetiteljski potencijali izlivali u uporedna, i međusobno nesaglasna kretanja romantičarskog pokreta, nastale su upravo u dramatičnom prilagođavanju novoj stvarnosti koje se odigravalo na kraju XVII i počecima XVIII veka. Pored pravoslavnog, neovizantijskog ekskluzivizma, kosovskog i ruskog mita, ksenofobije, nekad i paranoje malog seljačkog društva koje se oblikovalo pod pritiscima „tuđinske“ vlasti, i sopstvenog klera koji je preuzeo i političku lidersku ulogu, srpska kultura se približavala srednjoevropskom baroku čije je ideološke i estetske karakteristike takođe bile daleke i teško razumljive. Taj proces je nagovestilo Kraljevstvo Slovena Mavra Orbinija, zahvaljujući intelektualnoj širini dubrovačkog pred-ilirizma. Tokom Dugog rata 1593-1606. pojavile su se, međutim, i prve naznake klerikalizacije srpske nacionalne politike obnovom kulta Svetog Save. Osnivanje Kongregacije za propagandu vere 1622. izazvalo je organizovan otpor srpskog klera, koji je sredinom XVI veka sarađivao sa osmanskim vlastima radeći na obnovi Pećke patrijaršije 1557.

Krajem XVI veka nastupio je verovatno prvi u nizu istorijskih preloma koji su srpsku kulturu okretali već davnoj feudalnoj prošlosti, čineći je sve manje sklonom da se prilagodava savremenim sistemima, dok je tragala za jednom izuzetnom ulogom naroda i njegove istorije. Upravo u epohi racionalizma sazrevao je jedan poseban mentalitet, koji je svoje orijentalne karakteristike sticao i u naknadnom usvajanju vizantijskog predanja, i odbacivanjem svake buduće podložnosti osmanskom sistemu. Taj mentalitet verovatno nije dovoljno ispitan. Nedostatak izvora bio je manje važan od nesklonosti jedne kulture da preispituje ona svoja ograničenja koja naizgled duguje tradiciji. Smena vizantijskog i osmanskog uticaja neoprezno se svodila na sukob civilizacija, mada je proces bio dug, $s$ primetnim odsustvom onih tektonskih poremećaja koje izazvao prvi pad Carigrada 1204. i pojava novih teritorijalnih celina koje su osnivali zapadni osvajači i koje su, ispostavilo se, bile samo privremene. I u srpsku kulturu ostao je urezan onaj strah, onaj otpor, zapadnim, rimskim uticajima, kojima je bila obuzeta prethodno Vizantija dok je, od "prve evropske renesanse“ sredinom XI osećala nova zapadna kulturna strujanja, da bi vremenom osećala i sve jači pritisak ekonomski superiornih sistema Venecije i Đenove koji su doprineli krizi i dezintegraciji vizantijskog feudalizma, tačnije, zapravo, njegovoj docnijoj tranziciji u osmanski sistem.

Osmanski prodor je, međutim, podsticao jedno veliko etničko pomeranje prema dubinama Podunavlja, koje je zahvatilo sve balkanske narode. Političke i kulturne implikacije tog procesa, bez obzira na okolnosti u kojima je bio spontan, nekad i gotovo neprimetan, proizvodile su političke i kulturne traume. Elite su dobile priliku da manipulišu krizama identiteta. Negovanje prošlosti, obično idealizirane, ili u svakom smislu krivotvorene, pre svega sredstvo vlasti i duhovnih manipulacija, prolagođavalo se novoj stvarnosti koja je nametala nove ideološke i estetske formate.

U takvim okolnostima rađala se kultura srpskog baroka. U nedostatku druge modernizacijske osnovice, srpsko prosvetiteljstvo bi se verovatno najpreciznije tumačilo procesima svojih baroknih preobražaja.

Uporedo sa očuvanjem ideološkog i estetskog kontinuiteta s feudalnom epohom, klerikalne i svetovne elite unosile su svoje nove potrebe i porive u sadržaj kolektivne mitologije i identiteta. Time se srpska nacionalna politika oblikovala pod pritiskom etičkih imperativa koji su povremeno ometali prilagođavanje stvarnosti. Od kraja XVI veka dugoročno je obustavljena saradnja sa osmanskim vlastima, i obnovljena je tek sredinom XVIII veka. Zaoštravanje odnosa odigralo se pod pritiskom hrišćanskih sila na Osmansko carstvo. Ali je njihova pojava bila već dovoljno daleka od idealiziranih sećanja na srpsko srednjovekovno carstvo. Dalekosežne ideologije postale su važan segment Dugog rata. Paradoksi toga vremena jasno se čitaju i na samim počecima epohe srpskog baroka, koji su usledili na kra- 
ju XVII veka. Ekonomska kriza, slabost centralne vlasti i počeci dezintegracije feudalnog sistema bili su opšti uslovi prestanka snošljivosti osmanskog režima. Osmansko carstvo je postajalo u jednome novom smislu problem u međunarodnim odnosima, kao nepredvidivo u svojoj i nestabilnosti. Tako je, vremenom, svedeno na predmet, od nekadašnjeg gotovo nezaobilaznog činioca tih odnosa.

"Svaki potres, od koga bi se ukazale pukotine na zdanju osmanske države, dovodio je pokorene narode, poglavito njihove odgovorne ljude, u novo iskušenje da se pokuša naći izlaz iz potčinjenosti tuđinu. Sve ovo može zazvučati čudnovato kad se uzme u obzir da pravni i društveni okrivi pojedinih naroda u Turskoj nisu bili teže podnošljivi od onih u okolnim hrišćanskim državama. Prelazeći na zemljište Habzburške Monarhije ili Mletačke republike, prebezi iz Turske su zahtevali da im se, u naknadu za njihovu vojnu službu, daruju povlastice slične onima koje su uživali u Turskoj. Procenat pravoslavnih koji su u Turskoj primili islam manji je od procenta pravoslavnih koji su u Austriji i Mletačkoj republici prevedeni u krilo rimske crkve.» ${ }^{1}$ Jedna od naizgled paradoksalnih pojava, koje je potrebno ispitati kako bi se razumela složena ideološka i estetska struktura u kontinuitetu srpske kulture baroka i prosvetiteljstva, verovatno je u okolnostima u kojima je veliki deo srpskog društva, pod austrijskom i mletačkom vladavinom, prvi put u istoriji pripao domenu individualnih sloboda. Stvarnost tih sloboda počela je, međutim, izmicati dometima ideološkog, duhovnog i ekonomskog nadzora onih srpskih elita koje su, suočene sa okolnostima razvoja srpskog građanstva u Podunavlju, nastojale da očuvaju tradicionalne, naročito ruske i slovenske, kao neo-vizantijske, kulturne i ideološke karakteristike toga društva. U takvim, složenim, smutnim prilikama, i za docnije generacije teško razumljivim, nastale su i Hronike Đorđa Brankovića. Njihovom pojavom postala je moguća i moderna obnova srpske istoriografije, koja je istovremeno počela pripadati evropskoj kulturi svoga vremena, mada na njenim marginama.

Hronike Đorđa Brankovića osvetlile su upravo tu novu slojevitost u srpskoj kulturi koja je otkrivala preplitanje lične i kolektivne mitologije, emocija, težnji, frustracija. (I nakon pojave zametaka prve moderne države, odsustvo sposobnosti da se razume priroda svoga vremena je srpske nacionalne zahteve odbacivalo na periferiju svakog evropskog poretka, ili su ih činile neprimerenim uređenju međunarodnih odnosa i njihovim vladajućim merilima.) Hronike su istovremeno bile izraz posebnosti barokne epohe. Nacionalna mitologija koja se oslanjala na predmoderno feudalno nasleđe i kult Nemanjića podsticala je apsolutističke težnje i genealoške pretenzije. Hronike su i jedan sasvim ličan politički program, koji je istoriju postavio u svrhu ostvarenja i ličnih ambicija i nacionalnog ujedinjenja. Opravdanje se traži u dalekoj prošlosti, ali naredni sloj Hronika uspostavlja neposredniju vezu sa stvarnošću. Nakon potiskivanja Osmanskog carstva iz Podunavlja, političko liderstvo se moglo ostvariti jedino uspehom u pregovorima koji bi obezbedili povoljniji srpski status u Habzburškoj monarhiji. Najzad, treći sloj ponovo napušta okvire realne politike i racionalnih interesa. Branković je trajno rešenje nacionalnog pitanja klerikalizovao i mitologizirao zahtevom za stvaranjem jedne velike pravoslavne države u jugoistočnoj Evropi. Njegov ilirizam podrazumeva izmirenje težnji i potreba nekoliko srodnih naroda, koji bi prihvatili upravo srpsko srednjovekovno nasleđe, time i logiku srpske prednacionalne mitologije.

Radovan SAMARDŽIĆ, „Đorđe Branković. Istorijske i političke osnove prvoga srpskog programa“, Pisci srpske istorije, Beograd, 2009, 67. 
Hronike su, sa svojim piscem, u istoriju srpske kulture unele važne nedoumice, nekad i paradokse. One su istovremeno prvi celovit narativ srpske i južnoslovenske istorije koji se pojavio na jeziku bliskom govornom, narodnom, koji se tokom XVII veka ostvario u epopejama Kandijskog i Morejskog rata, okupljenim, docnije, u Trećoj knjizi Srpskih narodnih pjesama Vuka Stef. Karadžića. ${ }^{2}$ „Srbi su u XVIII vek ušli sa dva jezička izraza u pismenosti, srpskoslovenskim i narodnim. To dvojstvo je oko 1700. godine imalo već petovekovnu tradiciju“. ${ }^{3}$ Tumačenja toga dvojstva (slično tome, docnije, i dva pisma), doticala su se suštine nacionalnog identiteta i kulture. Srpskoslovenski, koji se približavao ruskom, postao je jezik srpskog prosvetiteljstva, koji se razvijao na području Habzburške monarhije. Narodni govor, izvorno blizak dubrovačkom (hercegovačkom) - koji se docnije, tokom XIX veka, transformisao u kontekstu nove, ,beogradske varijante, postajao je jezik moderne države. Veoma je indikativan uporedni primer književnosti franjevaca u Bosni XVII i XVIII veka, na narodnom jeziku, štampane ili preštampavane ćirilicom. Upravo je ta književnost uticala na Dositeja da se odluči za narodni jezik. Drugi primer su moderni srpski jezik, i ćirilično pismo, koje je Vuk Stef. Karadžić preuzeo iz govora Dubrovnika i zaleđa koji su se vekovima unazad beležili, i tako čuvali i razvijali, i na latinici i na glagoljici itd.

Modernoj srpskoj kulturi sopstveni prosvetiteljski diskurs postajao je sve udaljeniji i manje razumljiv, tako da prosvetiteljstvo, s prvobitnim srpskim barokom, nije dovoljno učestvovalo u procesima evropeizacije i modernizacije. Ukoliko je zaista bila „zanimljiv izuzetak u okvirima evropske istoriografije“, pošto se javila i vekovima razvijala u „tako izuzetnim političkim, društvenim i kulturnim prilikama“, traganje za njenim mestom „u okvirima evropske istorijske misli“ "još uvek nije dovelo do jasnih odgovora na njenu ulogu u „nacionalnoj i političkoj emancipaciji naroda kojem je pripadala“. ${ }^{4}$ Slična logika istorijskog paradoksa bila je u prenošenju znanja i pismenosti u Beč, bez obzira na odnos Beča prema srpskom pitanju, i bez obzira na odnos pripadnika srpske elite prema austrijskoj carevini.

Usporeno sazrevanje srpske kulture, koja je upravo lišena, njihovom posebnošću, ili marginalizacijom, važnih modernizacijskih slojeva, ogleda se i u odnosu prema samoj pojavi Đorđa Brankovića. Ilarion Ruvarac je isticao njegove groteskne osobine, ne uviđajući složenost karaktera, prilika i barokne kulture. Branković je pripadao njenoj dalekoj periferiji. Ako je Branković ponudio, nakon Orbinija, prvi celovit narativ srpske istorije, Ruvarac je, svojom kritikom Brankovića, ustanovio jedan od obrazaca njenog nerazumevanja koji se, podveden pod paradigmu nacionalnog identiteta, sve isključivijeg u odnosu na evropski modernistički kontekst, ponekad svodio na vulgarno odbacivanje istorijskih slojeva koji su pripadali strukuturi Habzburške monarhije. Drugim rečima, Ruvarac je ustanovio karakterističnu shemu „kritičke škole“ srpske istoriografije, jednoga deintelektualiziranog pozivitizma koji se, od Ruvarčevog vremena, zasniva na utvrđivanju činjenica lišenih racionalnog i dubinskog pronicanja u stvarnost koja obično nije odgovarala docnijim ideološkim obrascima. Na gotovo istovetnoj liniji mišljenja, potvrđujući da je njegovo poniranje u građu bilo vrednije od ideološkog klerikalizma, Jovan Radonić je, pretresajući njegove političke metamofoze, istakao kako je Branković zastupao interese erdeljskog kneza Apafija, uče-

2 Radovan SAMARDŽIĆ, „Vuk Stefanović Karadžić. Treća knjiga 'Srpskih narodnih pjesama’ Vuka Stefanovića Karadžića“" Pisci srpske istorije, 389-415.

3 Pavle IVIĆ i Aleksandar MLADENOVIĆ, „O jeziku kod Srba u razdoblju od 1699. do 1804.“, Istorija srpskog naroda, 4, II, Beograd, 1986, 69.

4 Radovan SAMARDŽIĆ, „Kraljevstvo Slovena u razvitku srpske istoriografije“, Kraljevstvo Slovena, Zrenjanin, 2006, CXVII-CXVIII. 
stvovao u njihovim pograničnim pregovorima s Turcima, zatim prešao na austrijsku stranu i učestvovao u zaveri protiv Apafija, da bi od najveće važnosti bio Brankovićev doživljaj Rusije gde je tek osetio da je Erdelj za njega tuđinska zemlja, a Rusija i slovinstvo su mu bliži. Radonić je smatrao da se Branković tek od zatočenja u Beču, 1689, „definitivno formirao kao Srbin“. Brankovićeve posebnosti preciznije je ustanovio Jovana Skerlić. Za njega je Branković bio ,jedini svetovnjak među piscima srpskoslovenske škole“, i „prvi radnik na modernoj istoriji srpskoj, čovek koji je dugo i jako uticao na razvoj srpske istoriografije“, ali i slab pisac „koji nije vladao srpskim jezikom i vrlo je slabo pisao srpski“. I Radonić je primetio da Branković nije u potpunosti znao nijedan jezik, a nastupao je, i u tome je bila njegova prednost i u politici i u nauci, tako da je ostavljao utisak veoma učenog poliglote, dok je njegov fond konkretnog izražavanja bio srpskoslovenski čija se, vremenom sve bleđa srednjovekovna osnovica, dopunjavala turcizmima, rusizmima i polonizmima. Veoma korisno bilo je i ukazivanje Jorja Tadića na Brankovićev ilirizam. Tadić je podsetio kako je Branković „prvi formulisao osnovne zahteve u borbi za postizanje političke autonomije i očuvanje verski slobode“, dok se u njemu provlačilo i živo osećanja zajednice svih slovenskih naroda, naročito „ilirskih “.5 Milorad Pavić je u jednom trenutku Brankovićevu pojavu i ulogu poistovetio s potrebama tek potonjeg vremena: „srpska barokna istoriografija bila je neprekidno u službi budućnosti svoga naroda, u energičnim nastojanjima da ga odbrani od pokušaja odnarođavanja u austrijskoj imperiji i mletačkoj republici i da mu pomogne da opstane pod turskom okupacijom“. Zapravo se dugo zanemarivalo da je, u traganju za nacionalnim identitetom u istoriografiji i kulturi srpskog baroka, koji je otvarao prostor epohi prosvetiteljstva, najvažnija pojava u složenoj zbrci ideoloških i identitetskih slojeva, u ukupnoj Brankovićevoj pojavi, bila njegova spremnost da u u svoje izlaganje unosi materijale iz usmenog epskog predanja. ${ }^{6}$

Hronike su uspostavile važan kontinuitet u odnosu na neposrednu prošlost i budućnost ispitivanja i promišljanja celine jedne istorije koja se vezivala za još uvek nejasan amalgam nacija okupljenih podzajedničkim ilirskim ili slovenskim imeniteljem. U tom smislu je najcelishodniji osvrt na Mavra Orbinija kojije u Pezaru 1601, na počecima epohe baroka, objavio Il Regno degli Slavi, prvu zajedničku istoriju Južnih Slovena. Posmatrač povlačenja južnoslovenskih zajednica u rudimentarne oblike života na isturenim granicama novih civilizacija, svedok zamiranja njihovih kultura, Orbini se, sa svojim prethodnikom, hvarskim dominikancem Vinkom Pribojevićem, ponekad smatra pretečom panslavizma i ideja južnoslovenskog okupljanja. Pod utiskom veličine i zamaha osmanskih osvajanja, Orbini se opirao i mletačkom i habzburškom imperijalizmu. Dok je, vođen porivima koji su bili i humanistički i antikvarni, lutao lavirintima mitova i etimologija, kod Orbinija je sazrelo jedno iskreno, široko rodoljublje koje ga je navodilo da Slovenima proglašava ne samo Ilire i Trčane, nego i sve rimske careve potekle s njegove strane Jadranskog mora. Svestan da se čitaocima obraća u razdoblju preloma i sudbonosnih odluka, u godinama razvučenog i konfuznog Dugog rata koji je na turskoj strani najavljivao neizvesnost i povremenu

Jorjo TADIĆ, „Đorđe Branković. Od baroka do klasicizma“, Srpska književnost u književnoj kritici, Beograd, 1966, 61-65.

6 Ilarion RUVARAC, Odlomci o grofu Đordu Brankoviću i Arseniju Crnojeviću patrijarhu. Beograd, 1986, 2; Jovan SKERLIĆ, Srpska književnost u XVIII veku, SKA, Beograd, 1909, 53-61; Istorija nove srpske književnosti, Beograd, 1953, 28; Jovan RADONIĆ. GrofĐorde Branković i njegovo vreme. Beograd, 1911, 137; Jorjo TADIĆ. Đorde Branković. Od baroka do klasicizma. Srpska književnost u književnoj kritici, Beograd, 1966, 61-65; Milorad PAVIĆ, Istorija srpske književnosti baroknog doba (XVII i XVIII vek), Beograd, 1970, 526; Jelka REĐEP, GrofĐorde Branković i usmeno predanje, Novi Sad, 1991, 243-293. 
anarhiju, Orbini nije skrivao sklonost da svoje srpske i hrvatske susede posmatra u dobronamernom jedinstvu koje bi trebalo da postane područje nove politike papskog Rima. Ali čim se njegov spis, zbog šizmatičkih pisaca koje je navodio baveći se istočnopravoslavnim svetom, našao na Indeksu zabranjenih knjiga, moglo se naslutiti da Sveta stolica ne prihvata njegovo razumevanje prošlosti i karaktera slovenske zajednice, koje je u sebi nosilo i osećanje za budućnost.

Cela jedna generacija protekla je od smrti grofa Đorđa Brankovića 1711. do pojave Stematografije Hristofora Žefarovića 1741, u kojoj su okupljeni simboli srpskih i ostalih ilirskih zemalja. Heraldika i mitologija Stematografije bile su takođe samo jedan sloj u porukama koje su otkrivale novu političku, ekonomsku i društvenu stvarnost nakon Beogradskog mira 1739. Strasti su se uzburkale novom srpskom seobom i austrijskim gubitkom Beograda. Ali obnova ratova Austrije i Turske nije suštinski omela nastanak, najmanje u ekonomskom smislu, jednoga gotovo jedinstvenog društva, sa obe strane granice. Liberalizacija trgovine i dunavske plovidbe iz 1718. podstakla je ujedinjavanje oko opipljivih, poslovnih interesa, srpskog građanstva u Podunavlju, i onog dela društva u Turskoj koje je svoj napredak nastojalo da obezbedi povlasticama koje je nudila habzburška vlast dok je podsticala doseljavanje i ulazak u vojnu službu. Srpska građanska kultura u Podunavlju je mogla videti podsticaj i u kontrastima, pre svega konfesionalnim, sa svojom okolinom. Ta okolnost nije važila samo za podunavske Srbe. Sam Žefarović rodio se u grčko-cincarskoj sredini.

Stematografija je odražavala opipljivu, narodnu stvarnost, koja je nastajala još u prevratima i smutnjama Dugog rata, da bi se i odnosi unutar dotad celovite, kao nedovoljno definisane i izgrađene narodne mase počeli remetiti tokom Kandijskog i Morejskog rata u epopejama koje su osvetlile prve razlike među tadašnjim Hrvatima, Srbima, Bošnjacima i Crnogorcima, bez obzira na svoj neposredan karakter albuma gravira i heraldike. Stematografija je i zbirka stihova, kojima se Žefarović ugledao i na pismene i nepismene, poznate ili zaboravljene pesnike koji su, preuzimajući i ulogu brižljivih hroničara, beležili događaje koje su njihovi junaci, ili prost puk, mogli smatrati važnim, nekad i sudbinskim. Ali ni Stematografija nije bila u tom smislu isključiva, da je težila nekoj rigidnoj karakterizaciji nacionalne identifikacije. Slično Andriji Zmajeviću koji je, u prethodnoj, Brankovićevoj generaciji, opevao dvorove Nemanjića na ostrvu pred Perastom, ili Dubrovčaninu Đuri Matijaševiću koji je slavio hrvatske, srpske, bošnjačke i ugarske junake, ili franjevcu Andriji Kačiću Miošiću, itd., Žefarović je u Stematografiji „dao stihovane pohvale predela Dušanovog carstva, uključujući i druge krajeve, sve do Hrvatske u pesničkim devizama uz grbove“. Konceptualna širina je Žefarovića svrstala i uz pesnike savremenike poput Vasilija Petrovića Njegoša, Jovana Rajića, Gavrila Stefanovića Venclovića, Zahariju Orfelina ili Jovana Čarnojevića, koji je ostavio spev na latinskom De bello Pannonico (1740). ${ }^{7}$

Grbovnik Stematografije je postao izvor za insignije srpske države koja se obnavljala, dok su, na putanji modernizacije, postajale sve snažnije težnje da se njen karakter mitologizira, klerikalizuje i podredi ruskom mitu koji je privlačio i srpske izbeglice koje su, već u narednoj generaciji, u ogromnom etničkom i prostornom okruženju, brzo i bez traga nestajale. Tu kulturno-ideološku konfuziju naročito je koristila Karlovačka mitropolija. Domen koji bi se mogao smatrati istorijskim neuspehom srpske prosvetiteljske kulture bila je obuzetost ruskim prodorom u srpski jezik koji je, u svojoj klerikalnoj varijanti, bio gotovo nerazumljiv. Jedan od nekoliko stotina naslova prosvetiteljske književnosti i istoriografije koji je uspeo da

Milorad PAVIĆ, „Srpska književnost baroka“, Istorija srpskog naroda, 4, II, Beograd, 1986, 179. 
se nametne savremenicima bila je Istorija Jovana Rajića koja je, štampana 1790. u Beču, postavila nove osnove nacionalne emancipacije koje su počeli prihvatati i ustanici nakon 1804.

Tokovi srpskog baroka i prosvetiteljstva, oni koji se iščitavaju u ideološkim porukama istoriografije i njenih odjeka u političkoj stvarnosti, postaju naizgled složeniji i, istovremeno, preciznije postavljeni, ukoliko se posmatraju iz vizure hrvatskog i, naročito, dubrovač$\operatorname{kog}$ ilirizma. ${ }^{8}$ Razbarušenost, visoki idealizam i opštost ideologija srpske i hrvatske istoriografije čine ih u svakom smislu baroknom. Istoriografija srpskog baroka prati se tek od, u svemu izuzetne, pojave grofa Đorđa Brankovića. Karakterologija njegovih ideja i poruka delimično pripada poslednjoj deceniji XVI veka, obeleženoj ideološkom fantastikom obnovljenih sanjarenja o krstaškom poduhvatu koji će okončati osmansku vladavinu i osloboditi hrišćanske narode i hrišćanske svetinje. Branković je takođe prerano pozivao na opšti oslobodilački pokret čiji je ilirizam najavljivao, vek ranije, nacionalni karakter Srpske revolucije, čiji se modernitet zasnivao i na ekonomskoj moći, sasvim skorašnjoj, političkog i vojnog liderstva, i na uvažavanju ideoloških, nekad i istoricističkih poruka srpskih prosvetitelja, čiji su koreni duboko u srpskom baroku. Gotovo sličnom putanjom je Vuk Stef. Karadžić, sa osloncem na Dositeja Obradovića koji je u pripadao i prethodnoj prosvetiteljskoj epohi, iskoračio u kulturu evropskog romantizma.

\section{$\cos$}

\section{Searching For National identity in the SERbian BAROQUE AND ENLIGHTENMENT}

In Serbian prerevolutionary society, confrontations between traditional Church hierarchy and emerging institutions of national self-government marked processes of national emancipation. An important dichotomy was a lack of ability of the oral Serbian culture, legitimized by the Serbian revolution, to adapt itself to the enlightened discourse of the traditionalist citizenry and clergy in towns along the Danube river, which were alienated from illiterate peasantry and insurgent society. National mythology was rooted in ideological appropriations of nationals epic songs, whose topics and heroes were shared with neighboring nations, and only modestly in rationalist historiographic researches. Nation was in both cases, Serbian and Croatian, an ideological construction related to South Slavic origin, ethnic cultural unity and fighting against Ottomans. Historiography of the Serbian baroque is in its origins related to an exceptional personality of Count Đorđe Branković. His ideas and messages belonged to the last decade of the $16^{\text {th }}$ century, characterized by fantastic ideological constructs and dreams upon a crusade which would end the Ottoman domination upon Christians and liberate them and their sacred places. Brankovic was mobilizing too early for a general liberation movement, announced by Illyrianism, and which was realized a century later in the course of the Serbian revolution. Its modernity was founded on realistic economic groun$\mathrm{ds}$, controled by its political and military leadership, as well as upon accaptance of ideological and historicist messages of Serbian enlightened intellectuals, who were deeply rooted in the Serbian baroque. Taking a similar way, Vuk Stefanović Karadžić, following and surpassing enlightened Dositej Obradović, announced a culture of Serbian Romanticism.

Keywords: national identiy, Serbs, Croats, historiography, culture, baroque, enlightenment“

Zrinka BLAŽEVIĆ, Ilirizam prije ilirizma, Zagreb, 2008, 319-336. 


\section{$\cos$}

\section{Literatura:}

BLAŽEVIĆ, Zrinka. Ilirizam prije ilirizma. Zagreb, 2008.

INGRAO, Charles. The Habsburg Monarchy 1618-1815. Cambridge, 1994.

Istorija srpskog naroda, 4, II, Beograd, 1986.

ORBIN, Mavro. Kraljevstvo Slovena. Zrenjanin, 2006.

PAVIĆ, Milorad. Istorija srpske književnosti baroknog doba (XVII i XVIII vek). Beograd, 1970.

RADONIĆ, Jovan. Grof Đorde Branković i njegovo vreme. Beograd, 1911.

RADONIĆ, Jovan. Đurad II Branković, „despot Ilirika“. Cetinje, 1955.

REĐEP, Jelka. GrofĐorde Branković i usmeno predanje. Novi Sad, 1991.

SAMARDŽIĆ, Radovan. „Đorđe Branković. Istorijske i političke osnove prvoga srpskog programa“. Pisci srpske istorije, Beograd, 2009.

SAMARDŽIĆ, Radovan. „Vuk Stefanović Karadžić. Treća knjiga 'Srpskih nadonih pjesama’ Vuka Stefanovića Karadžića“. Pisci srpske istorije, Beograd, 2009, 389-415.

SKERLIĆ, Jovan. Srpska književnost u XVIII veku. Srpska kraljevska akademija, Beograd, 1909.

SKERLIĆ, Jovan. Istorija nove srpske književnosti. Beograd, 1953.

TADIĆ, Jorjo. Đorđe Branković. „Od baroka do klasicizma“. Srpska književnost u književnoj kritici, Beograd, 1966. 